\title{
“IDEOLOGIA DE GÊNERO”: PÂNICOS MORAIS, SILÊNCIOS TAGARELAS E A (RE)PRODUÇÃO DE NORMAS BINÁRIAS DE GÊNERO
}

\author{
Camila Camargo Ferreira (UFGD - camilacamargoferreira@ gmail.com) \\ Márcio Mucedula Aguiar (UFGD - MarcioAguiar@ufgd.edu.br)
}

\begin{abstract}
RESUMO
No presente artigo, buscamos delinear a emergência do cenário de combate ao que tem sido chamado nos tensionamentos acerca das questões de gênero e sexualidade de "ideologia de gênero". Pretendemos identificar, a partir de uma análise genealógica foucaultiana, quais são as relações de poder e os regimes de saber/verdade que dão sustentação a esse fenômeno. Como foco de análise, nos debruçamos sobre os discursos que permeiam/compõem os projetos de lei apresentados no Congresso Nacional voltados à proibição da chamada "ideologia de gênero" e à instituição do Programa Escola Sem Partido nas principais diretrizes educacionais brasileiras. O objetivo é demonstrar que as articulações de forças conservadoras moralistas no Congresso acionam e são acionadas por pânicos morais em torno da presença das temáticas de gênero e de sexualidade no âmbito escolar, bem como, evidenciar o que se esconde e se mostra por detrás desse processo. Por meio de nossa análise apontamos que longe de figurarem como mecanismos de repressão, essas proposições têm uma função dual de poder, tanto jurídica como produtiva, que se articulam no sentido de proibir os temas de gênero e sexualidade na escola, por um lado, e, por outro, reiterar um determinado "regime" de podersaber-verdade sobre o binômio sexo-gênero que sustenta/reitera a matriz heterossexual. Sugerimos que os projetos de lei se tratam de dispositivos jurídicos centrados na imposição de um silenciamento tagarela, que fala sobre as normas e (in)coerências binárias de gênero muito mais do que as cala.
\end{abstract}

Palavras-chave: "Ideologia de gênero"; Heterossexualidade compulsória; Gênero.

\section{"GENDER IDEOLOGY": MORAL PANICS, CHATTY SILENCES AND THE (RE)PRODUCTION OF BINARY NORMS OF GENDER}

\begin{abstract}
In the present article the aim is to outline the emergency of the combat phenomenon which have been going on at the tension around gender and sexuality of "gender ideology", in order to seek and identify, from a Foucauldian family tree, what are the power relations and the scheme of know/truth in which it is based. As the focus, was given attention to the discourse which guide/sustain the draft bills presented in the National Congress aimed towards the prohibition of the so-called "gender ideology" and the insertion of the School Without Political Party Program on the main Brazilian educational guidelines. The aim is to demonstrate that the articulation of conservative moralist forces in the Congress trigger and are triggered by moral panics about the presence of the gender matters and sexuality on scholar context and highlight what is hidden behind this process. Through this analysis is pointed that, far from act as repression mechanism, these proposals have a dual role of power, juridical and productive, prohibiting gender and sexuality related themes at school. Furthermore, these mechanisms also reaffirm a certain "regime" of power-knowledge-truth over the sex-gender binomen, which sustains/enforces the heterosexual matrix. Is suggested that the bill drafts are juridic dispositives centered on imposition of a chatty silence, which says more about the norms and binary (in)coherence than it soothes.
\end{abstract}

Key-words: “Gender Ideology”; Compulsory heterosexuality; Gender. 


\section{INTRODUÇÃO}

Neste artigo buscamos oferecer uma compreensão de parte do cenário desenhado em torno das temáticas de gênero e sexualidade, amparado na construção de um discurso "antigênero" como resposta política às reivindicações por igualdade de gênero e pelos direitos da população LGBT - que, de certo modo, questionam o conjunto específico de saber estruturador da moral sexual, no qual se sustentam as formas hegemônicas da sexualidade e das relações de gênero. Ao considerar a multiplicidade dessas (re)emergências históricas, privilegiamos como foco de análise as narrativas que se desenrolam em torno da categoria política "ideologia de gênero" no campo educacional.

Procuramos assim, captar os discusos mobilizados nas tagarelices dos grupos conservadores para justificar a necessidade de afastar o gênero e a sexualidade, enquanto objetos de questionamento, do espaço escolar. Para tanto, tomamos como objeto de análise as propostas de lei apresentadas no Congresso Nacional, a partir de 2014, voltadas ao silenciamento dos temas de gênero e sexualidade no espaço escolar através da proibição do que se chama de "ideologia de gênero", bem como à instituição do Programa Escola Sem Partido nas políticas educacionais brasileiras.

O intuito é entender o que se esconde por detrás do receio dos grupos e setores conservadores e religiosos, com relação à discussão das questões de gênero e sexualidade no ambiente escolar. Como método de compreensão optamos pela genealogia foucaultiana dos discursos que compõem/circulam os projetos de lei voltados à proibição do que tem sido chamado de "ideologia de gênero." Para tanto, torna-se imprescindível, como sugere Foucault (1998: 108), interrogar esses discursos no nível "de sua produtividade tática (que efeitos recíprocos de poder e saber proporcionam)" e no nível "de sua integração estratégica (que conjuntura e que correlação de forças torna necessária sua utilização em tal ou qual episódio dos diversos confrontos produzidos)."

Sob tal perspectiva, as pistas deixadas por Foucault (2015: 111) indicam que não convêm tentativas de captar esses discursos através meramente dos textos das propostas de leis, porque eles não circulam de modo restrito apenas nas páginas desses documentos. Assim, os enunciados desses últimos não devem ser percebidos como simples tela de projeção dos 
discursos que os compõem (FOUCAULT, 2015: 111). Muito além, a realização do mapeamento dos discursos que permeiam os projetos de lei coloca como imperativo a compreensão das interrelações entre poder-saber-verdade que atuam na sua produção e das diversas relações de poder que os envolvem.

Isso porque, as formações discursivas e as narrativas são inerentes às relações de poder e estão imbricadas a uma multiplicidade de mecanismos de poder-saber. O poder é "como uma rede produtiva de forças que atravessa todo o corpo social, ele permeia, produz coisas, induz ao prazer, forma saber, produz discurso" (FOUCAULT, 1998: 08). Essa própria rede é formada por regimes de saber, de modo que há uma circularidade entre saber e poder. Ao mesmo tempo em que forma o saber, ele é produzido através do saber, seu exercício está ligado à enunciação de determinada verdade estabelecida pelo saber.

Sugerimos, através das propostas de lei, a operação de uma recomposição genealógica das narrativas que constituem o fenômeno discursivo e político da "ideologia de gênero" e, assim, situá-las em meio às relações de poder e dos dispositivos de saber-poder que as atravessam. É a partir desse movimento metodológico que buscamos entender a emergência da categoria acusatória "ideologia de gênero" através dos projetos de lei voltados para o silenciamento dos temas de gênero e sexualidade no campo da educação.

\section{PÂNICOS MORAIS E AS DISPUTAS PELA PRODUÇÃo DE CORPOS E PRÁTICAS SEXUAIS INTELIGÍVEIS}

Com a tramitação dos Planos de Educação ${ }^{1}$ nas casas legislativas, em 2014, as temáticas de gênero passaram a ter uma centralidade notória no debate público, essencialmente no que toca ao campo educacional. Nesse cenário, as políticas públicas de educação em gênero e

\footnotetext{
${ }^{1}$ A tramitação do Plano Nacional de Educação (PNE), em 2014, no Congresso Nacional foi marcada por uma calorosa disputa em torno da presença da temática de gênero e sexualidade do documento. Na deliberação final do documento, a Câmara dos Deputados votou favorável à retirada de todas as palavras gênero e orientação sexual do documento - foram suprimidas inclusive expressões como "gênero alimentício" e "gênero literário". No ano posterior, a tramitação dos Planos Estaduais e Municipais de Educação foi marcada pela mesma polêmica. Vários estados e municípios seguiram o exemplo do Congresso e retiraram a temática de gênero e sexualidade de seus Planos. A exclusão do tema dos Planos Estaduais de Educação contou com a pressão de grupos conservadores, das bancadas religiosas, com respaldo de parcela de igrejas evangélicas e da Igreja Católica. Para a oposição à presença da temática no documento, as expressões "gênero" e "orientação sexual" foram introduzidas no PNE com vistas a disseminar na sociedade civil uma "ideologia de gênero", corrente que visaria deturpar seus valores morais e religiosos.
} 
sexualidade entraram na mira de grupos conservadores e religiosos, que passaram a acusa-las de "ideologia de gênero". Por meio dessa expressão, as teorias de gênero são explicitadas como um conjunto de ideias que veiculam uma falsa compreensão de mundo acerca do sexo, dos corpos e do desejo. Na visão desses grupos, essa suposta ideologia objetiva a destruição da família através da desestabilização de certezas consagradas pela moralidade no que tange à sexualidade e ao gênero - elementos interpretados como resultantes da natureza.

Como consequência desse imaginário, a possibilidade de um sistema de ensino pautado no questionamento de preconceitos, discriminações e violências baseadas nos marcadores sociais de gênero e sexualidade se tornou objeto de "pânicos morais". Emergem, assim, investidas na defesa de uma moralidade sexual dominante contrárias à construção de uma agenda institucional voltada ao combate e à criminalização desses temas na escola, (des)caracterizados, nesse contexto, como “ideologia de gênero". Como parte da estratégia política do conservadorismo moral, várias proposições de lei têm sido apresentadas no Congresso Nacional e nas casas legislativas estaduais e municipais com o objetivo de avançar sobre as principais leis, documentos e diretrizes que balizam a educação no Brasil. Esses projetos, no intuito de institucionalizar práticas tagarelas de silenciamento, produzem leis que proíbem a abordagem e o questionamento dos marcadores sociais de gênero e de sexualidade por meio do campo educacional.

Chamamos essas práticas de tagarelas porque pressupomos que em jogo com a tramitação dessas propostas não está o fimm (nem o começo) da introdução do gênero e da sexualidade nas políticas de educação, mas diferentes estratégias de poder/saber que se articulam através das disputas em torno da presença desses temas no espaço escolar. Uma delas é a conjuração da expressão "ideologia de gênero" e os pânicos morais criados a sua volta para justificar a necessidade de combater no espaço escolar as temáticas de gênero e sexualidade.

O conceito de pânico moral denota fenômenos coletivos que emergem como evidência de uma preocupação social com elementos e comportamentos sociais identificados como ameaça ao status quo de uma sociedade em determinado momento histórico (MISKOLCI, 2008: 231). A partir dessa categoria, compreendemos as reações contrárias à abordagem das questões de gênero e sexualidade no espaço escolar como expressões de temores sociais, com 
relação à (des)estabilização dos regimes de saber-verdade amparadores do ordenamento social que confere inteligibilidade aos corpos, aos sujeitos, aos desejos e aos prazeres.

A emergência desses pânicos morais acerca do que se chama de "ideologia de gênero" está ligada a uma série de afloramentos históricos em que gênero e sexualidade aparecem, nos mais diversos contextos, como terrenos de enfrentamentos. De maneira mais ampla, o aparecimento dos projetos de lei centrados na proibição desses temas no espaço escolar deve ser considerado como parte de mais "um round no conflituoso processo de "cidadanização" de diferentes sujeitos sociais, cujas identidades articulam-se, seja na linguagem do gênero ("mulheres", "travestis", "transexuais femininos e masculinos"), seja na da sexualidade ou orientação sexual (“gays", "lésbicas" e "bissexuais") (CARRARA, 2015: 324).

Esse round se alicerça na intensificação do imperativo de falar sobre a sexualidade que opera na produção de um regime de saber-verdade sobre o sexo. Esse avivamento da "caça ao sexo" se dá pela atuação política desses sujeitos marcados pelas diferenças de gênero e sexualidade, captados pelo "dispositivo da sexualidade" como "figuras mistas de aliança desviada e sexualidade anormal" (FOUCAULT, 1998: 234). Partindo dessa sexualidade no interior da qual por tanto tempo se procurou colonizar e atravessar a existência, os corpos, as subjetividades e as práticas, os próprios sujeitos se organizam politicamente para ir em direção a outras afirmações (FOUCAULT, 1998: 234).

Os confrontos produzidos nesse âmbito, como aponta Miskolci (2007: 103), se constituem como fenômenos privilegiados para a compreensão do lugar de gays, lésbicas, mulheres e transgêneros em nossa sociedade. Eles emergem como a materialização de embates entre visões de mundo, valores sexuais e morais. De modo geral, se apresentam divididos entre a concepção de que a cidadania e os direitos humanos devem ser estendidos ao mais variado conjunto de indivíduos, e o entendimento de que apenas sujeitos enquadrados nas fronteiras dos valores e práticas sociais hegemônicas devem ser reconhecidos como cidadãos e seres humanos (MELLO, 2005: 19).

Dessa última visão irrompe uma série de reações contrárias ao processo de "cidadanização" das minorias sexuais e de gênero, que, comumente fundadas em bases religiosas, investem na defesa da família moderna, do casamento, da monogamia, da maternidade, do parentesco, da heterossexualidade, da diferença sexual e da complementariedade entre os sexos. Enfim, dos papéis sociais intrínsecos às identidades 
elaboradas como femininas e masculinas. "Essas reações costumam negar todas as transformações históricas que vêm apontando para a diversificação das representações e das práticas relativas" (MELLO, 2005: 39) ao campo da sexualidade e das relações de gênero, reificando como norma absoluta e universal um modelo de moralidade "que corresponde apenas às crenças, expectativas e vivências de um único agrupamento social específico" (MELLO, 2005: 39).

Os empreendimentos contrários às práticas e narrativas que colocam em xeque as normas (coerências) de gênero e de sexualidade se dão porque nossa sociedade construiu historicamente uma imagem de ameaça à ordem social em torno dos sujeitos não inteligíveis por esse universo simbólico e material (MISKOLCI, 2007: 104). Eles estão fortemente vinculados à interpretação de que o atendimento das demandas por direitos humanos em relação aos sujeitos políticos dos movimentos feministas e LGBT’S $^{2}$ podem provocar mudanças na sociedade, percebidas como perigosas para a manutenção do corpo social (MISKOLCI; CAMPANA, 2017: 725).

Essas reações podem ser evidenciadas como expressões de receios frente às possibilidades de questionamento dos fundamentos estruturadores do caráter natural da distinção biológica que asseguram a regulação dos corpos, dos comportamentos, práticas, desejo e da subjetividade. À vista disso, consideramos que as investidas contra a presença dos temas de gênero e sexualidade na escola se desenrolam em torno desse temor com relação à transformação dos regimes de saber-verdade do sexo e das mudanças sociais que podem ser operadas a partir daí. Por isso, podem ser compreendidas "por meio do mecanismo de resistência e controle da transformação societária conhecido como pânicos morais, [...] que emergem" como expressão "do medo social com relação às mudanças, especialmente as percebidas como repentinas e, talvez por isso mesmo, ameaçadoras" (MISKOLCI, 2007: 103).

Por detrás dos receios com relação ao conceito de gênero e sua presença na escola residem esforços pela reiteração e (re)produção desse conjunto específico de saber sobre o sexo e o gênero, elementos estruturadores da constituição dos sujeitos e da realidade social.

\footnotetext{
${ }^{2}$ Como a conjugalidade homossexual, o reconhecimento da homoparentalidade, a criminalização da lgbtfobia, o aborto, a educação sexual, o reconhecimento da identidade de gênero de travestis e transexuais, a promoção de políticas educacionais voltadas à igualdade sexual e de gênero, o reconhecimento da diferença e diversidade, bem como o combate das diversas formas de discriminação e violências baseadas na sexualidade e no gênero, como o machismo, a transfobia, a homofobia e lesbofobia.
} 
Nesse âmbito, a caracterização discursiva do conceito de gênero como "teoria/ideologia de gênero" tem consistido em uma estratégia para tornar a abordagem no espaço escolar um perigo a ser combatido em nome da defesa da compreensão de que a forma hegemônica da família moderna, a divisão dual dos sexos, as identidades de gênero e o desejo heterossexual são (re)ordenadas a partir de leis da natureza e da vontade divina. E, por esse motivo, inquestionáveis. Assim, o gênero é transformado em uma categoria homogênea - "a teoria de gênero" ou "ideologia de gênero" - e interpretado como subversão, desrespeito e negação dessa ordem natural das coisas, num movimento que nega a cientificidade aos estudos de gênero e da sexualidade e reafirma o protagonismo da natureza como um absoluto na ordenação dos corpos, dos sujeitos, dos desejos, dos prazeres e das condutas (ROSADONUNES, 2015: 1240).

Os termos "teoria" ou "ideologia de gênero", tomados como sinônimos, transformam-se em poderosos slogans políticos mobilizados por pânicos morais com relação às políticas públicas de educação e práticas pedagógicas voltadas à promoção dos direitos sexuais. Eles são utilizados estrategicamente para dar nome à abordagem dos temas de gênero e sexualidade pelas escolas, vista como a imposição de uma falsa compreensão do sexo e do gênero, que representa ameaça à moral sexual e a algumas estruturas sociais consagradas como padrão "natural", como a família moderna, o casamento, a monogamia, a heterossexualidade, os papéis sociais intrínsecos às identidades elaboradas como masculinas e femininas, etc (JUNQUEIRA, 2017: 26).

Rubin (2003: 36) aponta que os pânicos morais geralmente tomam uma preexistente estrutura discursiva em que se inventam vítimas para justificar a importância da reparação de um perigo imaginado. $\mathrm{O}$ acionamento da categoria "ideologia de gênero" para descrever a inserção dos temas de gênero e sexualidade nos documentos educacionais e no processo educativo se dá justamente nesse sentido. $\mathrm{O}$ pânico moral com relação à discussão desses temas nas escolas recorre a uma distorção política do conceito de gênero, que o coloca como uma ameaça à sociedade, para legitimar a necessidade de seu combate e, mais a fundo, espalhar capilarmente o receio de desestabilização do conjunto de moralidades que regulam o sexo.

O conjunto estratégico de saberes e práticas que se constituíram ao longo do século XVIII como uma tecnologia do sexo é responsável ainda, de maneira exitosa, pela forma 
como percebemos os corpos, os sujeitos, as práticas e os prazeres. Dela ninguém escapa, uma vez que se trata de um dos mais importantes dispositivos de poder da modernidade. Um poder que não se exerce e se abate sobre o indivíduo de maneira unilateral, mas permeia todo corpo social, produz subjetividades através de relações de poder que se exercem sobre os corpos, multiplicidades, movimentos, desejos e forças (FOUCAULT, 1998).

Dessa maneira, os embates acerca das questões de gênero e sexualidade capilarizam-se em várias direções, no ponto em que o poder remodela incessantemente a vida cotidiana, percorre os indivíduos, traçando neles suas atitudes, seus pensamentos, seus gestos, sua aprendizagem, seus discursos, sua percepção do mundo, etc (FOUCAULT, 1998: 131). Não existe possibilidade de não estarmos imbricados nesses tensionamentos à medida que existimos como sujeitos de sexualidade e gênero atravessados pelo poder nessa forma microfísica. Por isso, a oposição à ampliação dos direitos dos sujeitos minorizados por essas diferenciações gera "complacência e até mesmo o incentivo a atitudes discriminatórias não apenas em nível estatal e jurídico, mas no cotidiano de grupos estigmatizados socialmente" (MISKOLCI, 2007: 115).

É nesse campo que se dá a articulação sistemática de forças entre sujeitos e grupos sociais, no qual se movimentam contra a chamada "ideologia de gênero" na educação através de múltiplas estruturas de poder em busca de manter vivos e/ou resgatar valores e práticas sociais por eles cultuadas como parte de uma moralidade que deve ser preservada. É possível localizar nesse fenômeno um enorme receio com relação ao questionamento de verdades produzidas no interior dos dispositivos da sexualidade acerca do caráter natural do sexo, assim, essas narrativas afirmam confusamente que a "ideologia de gênero" está para além da forma de sexualidade considerada genuína - a heterossexualidade.

\section{OS PROJETOS DE LEI ENQUANTO DISPOSITIVOS DE SABER-PODER DA SEXUALIDADE E DAS (IN)COERÊNCIAS DE GÊNERO}

Desde 2014, os projetos de lei voltados para a proibição da chamada "ideologia de gênero" têm se espalhado capilarmente pelo Brasil, a partir de uma coalescência de linhas de forças que procura o atendimento de seus interesses por meio da articulação de diferentes mecanismos e canais políticos. Nas casas legislativas estaduais e municipais tramitam ou já 
tramitaram pelo menos 64 (sessenta e quatro) propostas nesse sentido entre 2014 e 2017 . No Congresso Nacional, foram apresentadas (11) onze propostas relacionadas à regulação da presença dos temas de gênero e sexualidade no espaço escolar, 10 (dez) são projetos de lei, 9 (nove) estão na Câmara dos Deputados e 1 (um) no Senado Federal, além de 1 (uma) Proposta de Emenda à Constituição (PEC) que tramita na Câmara.

É possível perceber que projetos apresentados no legislativo podem ser divididos em dois grupos, ou seja, os que são voltados para a proibição da chamada "ideologia de gênero", entendida como a promoção das discussões de gênero e sexualidade na escola, e aqueles que buscam a instituição do Programa Escola Sem Partido (ESP) na principal lei que baliza a educação no Brasil, a Lei de Diretrizes e Bases (LDB - Lei no 9394/1996). Chama a atenção nesse movimento o fato de que nos órgãos legislativos estaduais e municipais são preponderantes essas últimas propostas, enquanto que no Congresso apenas duas proposições foram apresentadas nesse sentido. Tal predomínio é indicativo dos entrelaçamentos entre os dois tipos de propostas ao longo das emergências históricas de gênero e sexualidade nos debates recentes sobre a educação no país, ligados de modo intrínseco às próprias articulações entre os grupos e forças políticas envolvidas na elaboração e apresentação dos projetos de leis.

Apesar de ser possível identificar essas distinções entre as propostas, as finalidades que as perpassam são as mesmas. Parte delas demanda o combate ao que é chamado de “doutrinação ideológica", por meio da instituição de uma "escola sem partido", e outra parte é direcionada ao silenciamento do espaço escolar sobre as questões de gênero e a sexualidade. No debate público todas são referidas como Projeto Escola Sem Partido, indicativo de que o ponto central e os mecanismos de saber acionados são os mesmos. Elas estão amparadas na sugestão de que a educação familiar deve ter precedência sobre a educação escolar e na proibição da discussão das temáticas de gênero e sexualidade, apontada em boa parte dos projetos como "ideologia de gênero".

$\mathrm{O}$ intuito que as costuram é garantir, via dispositivos jurídicos, que os sistemas de ensino promovam uma educação pautada na neutralidade do conhecimento e sejam orientados pelo respeito às convicções políticas, morais e religiosas dos/as estudantes e de suas famílias, independentemente de quais sejam elas. A escola, conforme os projetos, não deve tomar e transmitir partido acerca de questões que possam entrar em conflito com as crenças 
apreendidas pelos/as alunos/as no âmbito privado, especialmente as que estejam relacionadas ao campo do gênero e sexualidade.

Os projetos voltados para a proibição da "ideologia de gênero" são delineados a partir da alegação de que a discussão dessas temáticas no espaço escolar busca interferir no que é entendido e apresentado como o "natural" amadurecimento de gênero e da orientação sexual das crianças e adolescentes. Já os projetos voltados para a instituição de uma "escola sem partido" estão baseados na objeção ao que é chamado de "doutrinação ideológica", política e de gênero nas escolas brasileiras. A expressão é caracterizada como um processo de manipulação dos/as alunos/as pelos/professores que teria como finalidade influenciar os primeiros na adoção de certo posicionamento político partidário e no questionamento da apontada "natural" orientação sexual e de gênero e moral religiosa e sexual ensinada pelos pais.

O que se busca com esses dispositivos jurídicos é a institucionalização nas principais leis e diretrizes que orientam a educação no Brasil de uma "escola sem partido", articulada à proibição da discussão dos temas de gênero e sexualidade, caracterizados de maneira pejorativa nesse contexto como "ideologia de gênero". Nesse aspecto as propostas quase se confundem, isto é, os projetos voltados para a instituição do Programa Escola Sem Partido, o PL 867/2015 e PLS 193/2016, bem como a maioria dos projetos que tramitam nos órgãos legislativos e estaduais, definem que a educação nacional deverá ser promovida com base no princípio do "direito dos pais a que seus filhos recebam a educação moral que esteja de acordo com suas próprias convicções" (CÂMARA DOS DEPUTADOS, 2015: 1; SENADO FEDERAL, 2016: 1).

O PL 867/2015 é de autoria do deputado Izalci Lucas (PSDB-DF). O parlamentar é membro das bancadas ${ }^{3}$ religiosas evangélica/católica e esteve diretamente ligado à tramitação de proposições polêmicas que envolvem a educação no Brasil. Ele se colocou assiduamente contrário à especificação de gênero e sexualidade na diretriz do PNE que apresenta como objetivo a superação das desigualdades educacionais. Já o PLS 193/2016 é do senador Magno Malta (PR-ES), pastor da Igreja Batista, presidente da Frente Parlamentar em Defesa da Família. O parlamentar é autor de outras proposições em que as questões de gênero e a

\footnotetext{
${ }^{3}$ Bancada é o termo usado pela linguagem técnica do nosso Legislativo federal como sinônimo de "Frente Parlamentar".
} 
sexualidade figuram como áreas de polêmicas, como o PLS 470/2013, que dispõem sobre o Estatuto das Famílias ${ }^{4}$.

Ambos estabelecem também que "são vedadas, em sala de aula, a prática de doutrinação política e ideológica bem como a veiculação de conteúdos ou a realização de atividades que possam estar em conflito com as convicções religiosas ou morais dos pais ou responsáveis pelos estudantes" (CÂMARA DOS DEPUTADOS, 2015: 1) E por fim, no tocante às questões de gênero e sexualidade, dispõe que:

O Poder Público não se imiscuirá na orientação sexual dos alunos nem permitirá qualquer prática capaz de comprometer, precipitar ou direcionar o natural amadurecimento e desenvolvimento de sua personalidade, em harmonia com a respectiva identidade biológica de sexo, sendo vedada, especialmente, a aplicação dos postulados da teoria ou ideologia de gênero (SENADO FEDERAL, 2016: 1). (Grifos nossos)

Destaca-se nesse artigo um saber sobre o sexo que o entende como pertencente aos domínios da natureza, pois recorre ao determinismo biológico - "a identidade biológica do sexo" - para naturalizar uma relação determinada entre o corpo, a personalidade e o comportamento. Uma perspectiva que enraíza na natureza a constituição de sujeitos femininos e masculinos, e então, as diferenças estabelecidas entre ambos e um tipo de desejo próprio, o heterossexual, que se realiza a partir dessa distinção. É no interior desse saber que é construída, como demonstra Foucault (2013) ao falar dos dispositivos da sexualidade, a "verdade" dos sujeitos. É em torno da reificação e (re)produção da "essencialização da natureza" que giram os projetos de lei. Esse imperativo de reafirmação dessa "verdade" se dá por conta de um receio de que a discussão de gênero e sexualidade nas escolas possam afetar o desenvolvimento dessa coerência entendida como natural entre corpo, gênero e desejo.

O imperativo da supremacia do espaço privado sobre o público no que tange à educação moral e sexual se repete em outros projetos de lei, como no PL 7180/2014 e PL 7181/2014 do deputado Erivelton Santana (PEN-BA), membro da Igreja Assembleia de Deus e da Frente Parlamentar Evangélica. O parlamentar se coloca avidamente como um soldado de Deus, defensor da família, das igrejas evangélicas, da vida e dos princípios e valores cristãos (SANTANA, 2014: s/p). Como parte de sua agenda política, está o combate à presença dos

\footnotetext{
${ }^{4}$ O PLS 470/2013 busca garantir o reconhecimento da família no Brasil a partir da união estável entre homens e mulheres, excluindo outros arranjos familiares que não fazem parte do modelo hegemônico moderno de família.
} 
temas de gênero e sexualidade na educação, para ele a "apologia ao crime de pedofilia e ideologia de gênero promovidas pela agenda nefasta de destruição da família devem ser combatidas no campo da ação e requer uma atitude" (PATRIOTA51, 2017: s/p) Sua fala deixa evidente e alimenta o pânico moral em torno da presença dos temas de gênero e sexualidade, principalmente no acionamento do receio à pedofilia, discurso que atravessa comumente as demandas pelo reconhecimento da população LGBT. Historicamente a sexualidade de gays e lésbicas é associada pelo imaginário social à promiscuidade e/ou "ao desenvolvimento de práticas ilícitas como a pedofilia” (MISKOLCI, 2007: 118).

"A política simbólica que estrutura os pânicos morais costuma se dar por meio da substituição, ou seja, grupos de interesse ou empreendedores morais chamam a atenção para um assunto, porque ele representa, na verdade outra questão" (MISKOLCI, 2007: 114). O posicionamento do deputado Erivelton Santana é exemplar nesse sentido, que articula como mecanismo para denunciar a discussão dos temas de gênero e sexualidade no espaço escola, entendida como a propagação de uma "ideologia de gênero", o temor à pedofilia, ou seja, busca destacar o perigo da "ideologia de gênero" por meio do acionamento do pânico coletivo com relação à pedofilia. O PL 7180/2014 do deputado prevê que

a escola, o currículo escolar e o trabalho pedagógico realizado pelos professores em sala de aula não deve entrar no campo das convicções pessoais e valores familiares dos alunos da educação básica. Esses são temas para serem tratados na esfera privada, em que cada família cumpre o papel que a própria Constituição lhe outorga de participar na educação dos seus membros (CÂMARA DOS DEPUTADOS, 2014: 2).

A sugestão é de que a abordagem dos temas de gênero e sexualidade no espaço escolar fere determinados valores morais, familiares e religiosos pautados numa concepção biológica da constituição dos corpos, dos desejos, dos comportamentos e práticas sexuais. Essa lógica biologicista entende que as pessoas que nascem com uma vagina são mulheres e as que nascem com um pênis são homens, por natureza, ou seja, que o órgão genital determina a identidade de gênero e também o desejo centrado na lógica de que os opostos se atraem homens estão naturalmente para as mulheres, como as mulheres estão naturalmente para os homens. A constituição e inteligibilidade do sujeito humano passa por essa lente de enquadramento que determina a partir de categorias essencializantes - "homem" e "mulher" o desejo heterossexual. 
Em consonância com os projetos do Escola Sem Partido está também o PL 1411/2015, do deputado Rogério Marinho (PSDB-RN), que apesar de não compor nenhuma das bancadas religiosas, se coloca no debate público como católico e ávido defensor dos valores cristãos e morais. A sua proposta tipifica como crime de "assédio ideológico", caraterizado de maneira muito próxima ao que o MESP nomeia de "doutrinação política e ideológica", como se pode concluir pela definição apresentada no projeto:

Entende-se como Assédio Ideológico toda prática que condicione o aluno a adotar determinado posicionamento político, partidário, ideológico ou qualquer tipo de constrangimento causado por outrem ao aluno por adotar posicionamento diverso do seu, independente de quem seja o agente (CÂMARA DOS DEPUTADOS, 2015: 2).

De acordo com a justificativa da proposta o Partido dos Trabalhadores (PT) estaria se utilizando dessa forma de assédio ideológico para pregar "guerra aos que pensam como a maioria da população brasileira em temas como segurança, educação e valores da família" (CÂMARA DOS DEPUTADOS, 2015: 3), relacionados à redução da maioridade penal, a legalização do aborto, a criminalização da homofobia, a união homoafetiva, etc. O autor destaca que é também através do assédio ideológico que o PT busca convencer sobre a importância das mudanças políticas, econômicas e sociais para combater os avanços do neoliberalismo e do conservadorismo na sociedade brasileira.

O projeto é muito similar ao PL 867/2015 e ao PLS 193/2016, mas no lugar de "doutrinação ideológica", aparece como foco o combate ao que é chamado de "assédio ideológico", por meio dos mesmos dispositivos jurídicos. O que o diferencia dos demais é a presença explícita de narrativas "antipetistas", de modo que fica evidente a mescla entre o discurso "antipetista" e o combate à "ideologia de gênero". A partir dessa constatação, é possível apontar que é como resultado dessa articulação complexa entre luta contra a “doutrinação ideológica" (política e de gênero) e da reação do Partido dos Trabalhadores que surge o PL 1411/2015 e os demais projetos. Nessa conexão destacam-se discursos que associam a abordagem dos temas de gênero e sexualidade com o comunismo, alegando a existência de uma conspiração comunista para destruir a família e enfraquecer a Nação (RUBIN, 2003: 9). 
Esse é um temor social antigo, a partir do qual há uma interligação entre batalhas anticomunistas internacionais com lutas contra comportamentos e grupos sexuais considerados como "imorais" (RUBIN, 2003: 09). Tais pânicos morais estão associados ao fato de que "historicamente, grupos sociais estigmatizados por sua religião, visão política ou orientação sexual são socialmente representados como perigo para" (MISKOLCI, 2007: 109) as crianças, as famílias e a sociedade. Essa representação decorre do entendimento de que seus ideais, estilos de vida, comportamentos e práticas sexuais podem provocar alterações profundas nas tramas das sociedades se não foram controladas. Nesse sentido, por exemplo, "é notória a construção da imagem" dos comunistas como "devoradores de criancinhas". No caso dos homens gays, a de imagem de perigo os associa à pedofilia" e a perversão (MISKOLCI, 2007: 109).

A conexão entre narrativas "antigênero" e da partidarização do ensino que aparece nas propostas de lei estão vinculadas a esse imaginário, de modo que elas (re)produzem esses temores e se empenham no seu controle a partir de genuínas cruzadas morais. De modo mais ou menos explícito, ela emerge em diversos cenários políticos, como por exemplo na votação do impeachment da presidenta da República, Dilma Rousseff, em 2016. Miguel (2016: 611) aponta que três deputados justificaram seus votos favoráveis ao afastamento da presidenta com argumentos ligados à doutrinação na escola e à "ideologia de gênero". Rogério Marinho (PSDB-RN), autor do PL 1411/2015, afirmou seu voto contra o PT, porque o partido "se utiliza da política externa nacional para financiar ditaduras bolivarianas sanguinárias" e "da educação para doutrinar e assediar nossas crianças" (ROGÉRIO MARINHO, PSDB-RN, Sessão de 17/04/2016 apud MIGUEL, 2016: 612).

Seffner (2016: 2) aponta que "os mandatos do PT na presidência da república parecem ter ficado marcados pela proposição de políticas públicas de educação em gênero e sexualidade, o que atiçou os fantasmas e o pânico moral de coisas tão fabulosas como "mudar o sexo das crianças nas escolas" (SEFFNER, 2016: 2). É nessa senda que se somam aos projetos que proíbem a chamada "doutrinação ideológica", nos quais aparece de modo implícito o silenciamento da discussão dos temas de gênero e sexualidade no espaço escolar, propostas voltadas explicitamente para a proibição da chamada "ideologia de gênero".

É o caso do PL 1859 de autoria do deputado já citado Izalci Lucas (PSDB-DF), apresentado na Câmara em 2015. A proposta é construída, em grande parte, em torno do 
pânico moral disseminado pela Igreja Católica acerca da "ideologia de gênero", , de modo que ela recorre aos discursos propalados em documentos, livros e sites católicos sobre as questões relativas ao gênero e a sexualidade. O objetivo da proposição é tornar ilegal a disseminação da chamada "ideologia de gênero", que se sustenta por meio da deslegitimação das teorias feministas e dos estudos sobre o gênero e a sexualidade. A principal justificativa é de que as abordagens desses temas, baseadas nesse conhecimento, representam uma ameaça à família e à identidade do ser humano.

$\mathrm{Na}$ justificativa do projeto fica evidente que o alarde provocado pela "ideologia de gênero" se liga principalmente ao receio da desestabilização da inteligibilidade de gênero, que institui e mantem "relações de coerência e continuidade entre sexo, gênero, prática sexual e desejo" (BUTLER, 2016: 43). Isso porque fica evidente o entendimento de que a desordenação da coerência do sistema sexo/gênero/desejo conduz à destruição da instituição familiar. Ressalta-se nesses discursos que aa verdade mais profunda dos sujeitos humanos é centrada no seu sexo. Imagina-se que as teorias de gênero buscam desenvolver um mundo de genuína igualdade através da dissolução de categorias como "homem" e "mulher" e que sem elas o ser humano se tornaria sexualmente indefinido, "não existiria mais traços diferenciais entre o masculino e o feminino [...], todos teriam que ser educados como bissexuais e a masculinidade e a feminilidade deixariam de ser naturais." (CÂMARA DOS DEPUTADOS, 2015a: 11).

Por detrás desse pânico moral com relação à destruição da família há o receio do questionamento de verdades produzidas por uma Scientia Sexualis, descrita por Foucault (2015), acerca do caráter natural do sexo. O combate à “ideologia de gênero" está amparado no receio com relação às possibilidades de reconhecimento dos sujeitos que extrapolam os

\footnotetext{
${ }^{5}$ O termo "ideologia de gênero" ou "teoria de gênero" desponta nos contextos vaticanos como um rótulo político das demandas dos movimentos feministas e, posteriormente, também do movimento LGBT, apontadas comumente como ideologias radicais que objetivam destruir a família, na sua realização tradicional heterossexual, desvalorizar o ser humano na sua descaracterização como homem e mulher e, por consequência, ameaçando a existência da sociedade. Como apontam Miskolci e Campana (2017: 726) as origens das ideias que sustentam a existência de uma "ideologia de gênero" podem encontrar-se no seio da Igreja Católica, mais especificamente nos textos do então cardeal Joseph Aloisius Ratzinger" (Papa Bento XVI). Nesse cenário, sua emergência é fruto das reações da Igreja Católica com relação ao aceno da possibilidade da incorporação de uma perspectiva de gênero no desenho de políticas por órgãos nacionais e internacionais através da Conferência Mundial de Beijing sobre a Mulher organizada pelas Nações Unidas, em 1995. No contexto latino-americano, as obras do argentino Jorge Scala La ideología del género. O el género como herramienta de poder e Ideologia de gênero - o neototalitarismo e a morte da família exerceram influencia na capilarização do combate à chamada "ideologia de gênero.
} 
limites das formas de sexualidade e de existência aceitas socialmente como verdadeiras e naturais. Assim, ele é movimentado pela ameaça de que o sexo deixe de ser visto como elemento natural e fixo, o que tornaria impossível a demarcação e regulação da experiência sexual nos limites da "normalidade natural", do desvio e da "anormalidade".

O fenômeno discursivo e político que se desdobra em torno da categoria "ideologia de gênero" é construído através da influência de aparatos históricos e culturais de produção das diferenças sexuais, no interior dos quais

a instituição da heterossexualidade compulsória e naturalizada exige e regula o gênero como uma relação binária em que o termo masculino diferencia-se do termo feminino, realizando-se essa diferenciação por meio das práticas do desejo heterossexual. $\mathrm{O}$ ato de diferenciar os dois momentos oposicionais da estrutura binária resulta numa consolidação de cada um de seus termos, da coerência interna respectiva do sexo, do gênero e do desejo (BUTLER, 2016: 53).

Ao mesmo tempo, ele se constitui como um mecanismo de saber-poder a que recorrem os grupos conservadores em meio às disputas e tensionamentos que tangenciam as significações da sexualidade para assegurar a capilaridade dessa matriz heterossexual. Nesse sentido, como um mecanismo de controle dos perigos da "ideologia de gênero", que tem como pano de fundo a manutenção dessa instituição heterossexual, o PL 1859/2015 propõe tornar lei a proibição da aplicação da "ideologia de gênero", bem como o termo de "gênero" ou “orientação sexual”.

$\mathrm{Na}$ proposição aparecem praticamente os mesmos discursos que marcaram a oposição às temáticas de gênero e sexualidade na educação durante a tramitação do PNE, como mostra um dos discursos proferidos pelo deputado Pastor Marco Feliciano (PSC-SP) ${ }^{6}$, no qual ele

\footnotetext{
${ }^{6}$ O deputado Marco Feliciano, eleito em 2010, é pastor da igreja Assembleia de Deus Catedral do Avivamento. Membro da Frente Parlamentar Evangélica, o parlamentar apresentou questões de cunho religioso na maioria de suas proposições (GONÇALVES, 2017: 215). Destacou-se no cenário nacional por polêmicas declarações machistas, homofóbicas e racistas divulgadas em suas redes sociais, em entrevistas e pregações, que, "resumida e respectivamente, [...] estão relacionadas às seguintes opiniões de Feliciano: sobre a África - o deputado afirmou que, de acordo com a Bíblia, os africanos descendem de ancestrais amaldiçoados; a respeito das mulheres Feliciano comentou que é contra a luta das mulheres pela igualdade de direitos, pois essa igualdade levaria a humanidade ao seu fím e, com relação às declarações homofóbicas - Feliciano asseverou que a AIDS é um câncer gay" (GONÇALVES, 2017: 207). Ele se coloca abertamente no debate público como defensor da família, é crítico da militância LGBT e feminista e ativista de campanhas favoráveis à chamada "cura gay" e contrárias à chamada "ideologia de gênero". Em 2013, foi eleito presidente da Comissão de Direitos Humanos da Câmara dos Deputados (CDHM), na qual representou o interesse das bancadas religiosas nas disputas pelo delineamento das discussões acerca dos direitos humanos e dos grupos minoritários. Conforme Gonçalves (2017: 225-226), isso se evidencia pelo predomínio de membros da Frente Parlamentar Evangélica na CDHM, "que souberam utilizar estrategicamente a comissão para promover, em algumas circunstância, suas pautas motivadas por valores religiosos ou por questões que também são tratadas no interior das igrejas, como a valorização da
} 
aponta: "a ideologia de gênero é uma construção social da imagem sobre o ser humano, ou seja, o ser humano nasce um ser amorfo. Ele vai se descobrir homem ou mulher depois, quando tiver certa idade" (CÂMARA DOS DEPUTADOS, 2014a: 251). Nessas narrativas, as expressões gênero e orientação sexual são tomadas como sinônimas de "ideologia de gênero", como se todas tratassem da mesma coisa, de uma corrente derivada do marxismo que se trata de conspiração perigosa voltada para a destruição "sem precedentes" da família, para a diluição das identidades femininas e masculinas que visa transformar homens e mulheres em seres "amorfos" em termos de sua existência sexual.

Os sujeitos e os saberes que extrapolam a esses imperativos são interpretados como responsáveis por "desvalorizar o ser humano" naquilo que o forma enquanto tal, a identidade de gênero - feminino-masculino - em conformidade com a perfeita coerência (produzida) com o sexo - vagina-pênis - e a heterossexualidade. Por isso, a ideia de que esses sujeitos que não se adequam nessa constituição desqualificam o que é ser homem e o que é ser mulher. No limite, esses discursos sugerem que com a aplicação da "ideologia de gênero" a identidade humana seria dissolvida, pois não haveria mais a possibilidade de descrever as identidades sexuais dos sujeitos humanos a partir das categorias homem e mulher.

Nesse movimento, os temores com relação à "ideologia de gênero" giram em torno de genuína recusa ao empreendimento de desnaturalização das performatividades normativas heterocêntricas operada por parte das discussões de gênero ${ }^{7}$. Aflora, assim, o pânico em volta das possibilidades de embaralhamento das certezas pré-estabelecedoras de verdades biológicas que definem linhas muito rígidas no delineamento das subjetividades. Verdades essas que fixam a natureza como ordem legítima de sujeição dos corpos e do desejo, ao

família, o combate à pornografia, tráfico e o consumo de drogas e o aborto." Com relação ao legado de Feliciano à CDHM, Magali Cunha (2014 apud GONÇALVES, 2017: 226) constatou a tramitação de temas considerados questionáveis e irrelevantes para a defesa dos direitos humanos, principalmente das demandas do movimento LGBT. O parlamentar, por exemplo, advertia que a CDHM não daria mais prioridade aos temas voltados para os direitos dos homossexuais. Trata-se de um discurso utilizado pelo parlamentar na tentativa de justificar a sua atuação contrária aos direitos desse segmento com o propósito de colocar obstáculos para as pautas LGBTs. Durante a sua presidência, Feliciano adotou manobras para barrar essas pautas, por meio da apresentação de proposições polêmicas (Cura gay) e na rejeição do Projeto de Lei 6.297/2005, de autoria de Mauricio Rands (PT$\mathrm{PE})$, que pretendia incluir na situação jurídica de dependente, para fins previdenciários, o companheiro ou companheira homossexual do segurado ou segurada do INSS e o companheiro ou companheira homossexual do servidor(a) público(a) civil da União" (GONÇALVES, 2017: 226).

${ }^{7}$ Os estudos e as teorias de gênero não são campos homogêneos. Há correntes que, ao preservar o caráter natural do sexo intocável e reificar papéis femininos e masculinos, privilegiam uma leitura essencialista das relações de gênero, da produção dos corpos e do desejo. 
definirem como regra que o ser nasce (naturalmente) e é reconhecido como ser apenas enquanto masculino/feminino por meio de sexos opostos e complementares.

O sexo, nesse caso, se constitui como um dispositivo que assegura performaticamente o universo heterocêntrico. Por meio dessa tecnologia de poder, "a (hetero)sexualidade, longe de surgir espontaneamente de cada corpo recém-nascido, deve se reinscrever ou se reinstruir através de operações de repetição e recitação dos códigos (masculino e feminino) socialmente investidos como naturais" (PRECIADO, 2017: 26). Sustentados por esse dispositivo, os discursos contrários à "ideologia de gênero" (re)produzem ideia de que os sujeitos que não se adequem à matriz de inteligibilidade de gênero - ser homem ou ser mulher - não podem ser decifradas como pessoas, mas pelo it de Clarice Lispector (1938). Ou seja, como coisas, ou utilizando a expressão do deputado Marco Feliciano (PSC-SP), também acionada no PL 1859, "como seres amorfos", aquilo que não pode ser definido pelo pronome ele/ela. Essa preocupação com a pulverização das identidades femininas e masculinas está ligada ao fato de que:

A matriz cultural por meio da qual a identidade de gênero se torna inteligível exige certos tipos de "identidade que não possam existir" - isto é, aqueles em que o gênero decorre do sexo e aqueles em que as práticas do desejo não "decorrem" nem do "sexo" nem do "gênero". Nesse contexto, decorrer seria uma relação política de direito instituído pelas leis culturais que estabelecem e regulam a forma e o significado da sexualidade (BUTLER, 2016: 44).

As reivindicações de combate à "ideologia de gênero" decorrem da capilaridade dessa matriz cultural, pois elas emergem da ação política de grupos conservadores que buscam manter (conservar) essas normas de inteligibilidade socialmente instituídas por considera-las como elementos naturais e inquestionáveis. A justificativa da proposta abordada recorre a essa narrativa para apontar sobre os perigos da "ideologia de gênero" e justificar a necessidade de sua proibição

Foi [...] Judith Butler quem apresentou, no início dos anos 90, o conceito filosófico moderno de gênero, sob a forma que poderia ser aplicado, através do movimento feminista, para conduzir à destruição da família, necessária para promover a revolução socialista. Segundo Butler, quando as feministas se pensam a si mesmas como mulheres, já estão com isto, construindo um discurso que as impedem de emancipar-se dos homens. As feministas não deveriam mais falar da mulher como sujeito do seu movimento, mas deveriam, em vez disso, substituir tanto a feminilidade como a 
masculinidade pelo conceito amorfo e variável de gênero (CÂMARA DOS DEPUTADOS, 2015a: 7).

O PL se debruça sobre a "ideologia de gênero" relacionando as teorias de gênero ao marxismo e ao feminismo, que numa articulação suposta são apontados como empenhados na luta contra a instituição familiar. Desse modo, a proposição é alimentada pelo pânico moral que conecta o comunismo à "ideologia de gênero", no sentido de propor um veto à discussão de gênero e sexualidade na escola. Esconde-se por detrás desse imperativo repressivo um retorno à patologização dos sujeitos, das práticas, dos comportamentos, das relações amorosas e familiares que não se adequam à economia política da heterossexualidade. A ênfase no receio extremado com relação à destruição da família é dada como um meio para a obtenção de um controle sobre o sexo, que reflete nos corpos, nos sujeitos, nas subjetividades e nos desejos. Por isso, ao demarcar a ilegalidade da abordagem das questões de gênero e sexualidade,

o projeto impede que vastos setores do conhecimento produzido na sociologia e na psicologia cheguem ao ensino. A meta é evitar qualquer questionamento da percepção naturalizada dos papéis sexuais. Com isso, fica impedido o combate a formas recorrentes de violência ocasionada por gênero, dentro e fora da instituição escolar, culminando no feminicídio e no assassinato de gays, lésbicas e travestis. A defesa da instituição familiar, a "base da sociedade", é um objetivo que parece compensar tais problemas - que ficam completamente invisibilizados (MIGUEL, 2016: 608).

Proposta muito semelhante a anterior é o PL 2731/2015, de Eros Biondini (PROS-MG) - cantor gospel e membro da Frente Parlamentar Mista Apostólica Romana e da Frente Parlamentar Evangélica. O projeto objetiva a alteração do PNE para proibir "a utilização de qualquer tipo de ideologia na educação nacional, em especial o uso da ideologia de gênero, orientação sexual, identidade de gênero e seus derivados, sob qualquer pretexto" (CÂMARA DOS DEPUTADOS, 2015b: 1). Além disso, estabelece que os Estados, o Distrito Federal e os Municípios deverão adequar seus planos de educação à alteração no prazo de 30 a contar da data da publicação da lei (CÂMARA DOS DEPUTADOS, 2015b). O PL define ainda que "o não atendimento do prazo estabelecido neste artigo, impossibilitará o repasse de recursos financeiros federais, destinados à educação, ao ente federativo em atraso" (CÂMARA DOS DEPUTADOS, 2015b: 1) 
Articulado aos projetos descritos anteriormente, voltados para a retirada da chamada “ideologia de gênero" da cena educacional, está o PL 5487/2016, de autoria do deputado Victório Galli (PSC-MT), que proíbe o Ministério da Educação e da Cultura de "orientar e distribuir livros às escolas públicas que versem sobre a orientação sexual de crianças e adolescentes, em consonância com a Lei 13005/2014 do PNE" (CÂMARA DOS DEPUTADOS, 2016: 1). Engajado também na regulação das discussões acerca da sexualidade está o PL 8933/2017, de autoria do deputado Pastor Eurico (PHS-PE), que acrescenta ao art. 32 da lei nacional da educação (LDB - Lei no 9394/90) que "as disciplinas sobre educação sexual somente serão ministradas ao aluno casa haja a autorização dos pais ou responsáveis legais" (CÂMARA DOS DEPUTADOS, 2017: 1).

A proposição soma-se às outras como um dispositivo de controle dos limites da escola, enquanto espaço público, com relação à abordagem de temáticas da sexualidade, que reforça o papel família como detentora exclusiva do poder de educar moralmente os indivíduos menores, cabendo à escola somente auxílio nesse processo. Nela, reaparece o temor com relação à exposição de crianças e adolescentes à erotização e, o discurso de que cabe à família decidir o que deve ser ensinado a seus rebentos acerca da sexualidade. A justificativa do projeto recorre ao pânico moral construído ao redor do receio da destruição e da perca de centralidade da instituição familiar:

A sociedade brasileira tem vivido momentos muito delicados social, política e culturalmente nos últimos anos. Observamos que valores humanos básicos, principalmente aqueles relacionados à família, são constantemente diminuídos e desprezados por setores que se apresentam como "progressistas" perante a sociedade. Nesse sentido, é notável que o que o mundo tem apresentado como modelo de educação sexual - e que tentou ser adotado pelos últimos governos - é uma distorção, quando não uma completa negação, do plano que a maioria das famílias brasileiras cristãs entende como correto para a sexualidade humana. A fim de defender valores cristãos, entendemos caber à própria família decidir quando e como iniciar a criança em temas relacionados à sexualidade, uma vez que são os valores familiares que irão guiar o caminhar do infante na seara íntima e sexual por toda a sua vida adulta. Isso porque a escola é uma instituição que tem uma função subsidiária na educação das crianças. Ela não pode substituir a família e seus respectivos valores. A missão dessa instituição é, isso sim, ajudar na função educativa própria da família, especialmente durante a infância e adolescência. Logo, apresentamos o presente projeto de lei, para condicionar o ensino na escola sobre temas relativos à educação social à prévia autorização dos pais ou responsáveis legais da criança. Posicionamo-nos, dessa forma, ao lado da família. 
Buscamos deixar claro que educação sexual se trata em casa, com os pais, que conhecem a sensibilidade e particularidade de seus filhos. A educação moral é da família - e a escola, bem como a sociedade, deve perceber esse limite (CÂMARA DOS DEPUTADOS, 2017: 1-2). (Grifos nossos).

O grande temor é de que a escola possa contradizer os valores ensinados na esfera privada - reduzida à instituição família. A promoção de uma educação em gênero e sexualidade pautada no combate à discriminação e ao preconceito que atravessam as minorias sexuais se desdobra, em grande parte, no sentido de despatologizar esses sujeitos, ou seja, em demonstrar que não há nada de errado com eles a partir da desconstrução de uma moralidade que busca dizer o contrário. É justamente esse o receio que se esconde por detrás do receio de destruição da família, como bem demonstra a justificativa do PL 8933/2017, ao sugerir que o desenvolvimento das políticas públicas educacionais em gênero e sexualidade promove uma "distorção" e uma "completa negação" do que é considerado correto no campo da sexualidade humana pela suposta maioria da população brasileira.

Desconsidera-se, nesse caso, que o "certo" e o "errado" são valores sociais e culturais construídos socialmente no interior e a partir das relações de saber-poder. No campo da sexualidade, especialmente, esses valores se constituem como marcadores sociais, que implicam na discriminação e na violência dos diversos sujeitos e grupos sociais assinalados como "errados". A emergência desses discursos no debate público evidencia a capilaridade dos dispositivos de saber-poder que constroem o gênero e a sexualidade e demonstram, desse modo, a dimensão histórica, cultural e política da regulação dos sujeitos pelo sexo. Esse imperativo aparece claramente no emaranhado das propostas, de modo que salta aos olhos o fato de que em jogo na apresentação desses projetos de lei está a disputa pelas significações atribuídas às relações de gênero e à sexualidade que deve ir à escola. É nessa atribuição de sentidos que é possível localizar as estratégias de poder/saber e os diversos pontos de resistência que emanam de várias direções e contornam a agenda de gênero e sexualidade voltada para a educação.

Como se pode notar, evidencia-se na leitura das proposições a repetição e a complementaridade do teor dos projetos de lei, pois todas são costuradas pela demanda de institucionalização da proibição de quaisquer discussões ou saberes promovidos pela escola que possam ferir uma determinada moralidade que se mostra intimamente ligada a valores 
religiosos e políticos e a defesa do modelo de família moderna. O que as difere é o direcionamento de cada uma para as leis e diretrizes educacionais dos planos de governo. Por detrás dessa conectividade há a articulação de diversas linhas de forças e de diferentes estratégias que estão ligadas à emergência histórica de uma vinculação complexa entre grupos religiosos (e conservadores) mobilizada em torno da reação às temáticas de gênero e sexualidade e, em especial, da possibilidade de sua presença no campo educacional.

Nesse sentido, os projetos de lei resultam de uma movimentação "antigênero", expressão de um temor social com relação ao saber produzido pelos estudos e teorias de gênero. O conteúdo delas, (re)produzido em meio a cenários em que o gênero e a sexualidade figuram como áreas de disputas, apresenta como demanda o silenciamento das questões relacionadas a esses temas no campo da educação. Por isso, é possível inferir que elas despontam no cenário nacional como resistência ou de negação à incorporação desse tema no sistema educacional brasileiro, ordenadas como uma parte importante da luta contra o amplo processo de construção de uma agenda de políticas públicas educacionais, voltada para as questões de gênero e sexualidade. Cujo foco é a promoção da igualdade de acesso à educação entre meninos e meninas, para a discussão no espaço escolar das desigualdades de gênero, da diversidade sexual e para o combate ao preconceito, discriminação e violência baseadas nas práticas de gênero e nas de sexualidade.

Esse dado inicial, num primeiro instante, leva a crer que estamos diante de uma tentativa de silenciar o espaço escolar sobre os temas de gênero e sexualidade através dos projetos de lei, que buscam instituir uma "escola sem partido" (supostamente neutra) e que estabelecem a censura dessas temáticas sob a alegação de que o "espaço público" não é lugar adequado para tratar de quaisquer questões relacionadas a elas, uma vez que cabe à família, portanto ao "espaço privado", a educação moral dos/as estudantes. Entretanto, a articulação vista anteriormente entre poder, saber e verdade tecida por Foucault nos guia a não conceber essas propostas normativas como mecanismos reguladores que buscam meramente a repressão ou a censura da abordagem das relações de gênero e da sexualidade na escola, mas a perceber que elas são atravessadas por um duplo regime de poder, repressivo e produtivo.

É inegável que elas entram em cena através do exercício de um poder jurídico, que opera por meio de práticas repressivas, como a busca por tornar lei a proibição explícita - que beira à censura - da discussão das questões de gênero e sexualidade no sentido de impedir 
quaisquer debates que possam questionar a ordem discursiva "natural" do sexo, do gênero e do desejo. Mas há de se perceber que essas propostas abrangem, sobretudo, relações de poder produtivo que ampara a regulação das práticas e da subjetividade através da (re)produção de determinados modos de ser e estar no mundo que se tornam inteligíveis no interior de regimes de saber-verdade. De modo que é importante imaginar que por detrás deles está o imperativo de calar, mas ao mesmo tempo falar sobre o gênero, de produzir e reiterar um determinado regime de saber-verdade sobre as relações, as práticas e os corpos.

Dessa maneira, para além do plano jurídico e repressivo, as propostas de lei são atravessadas por uma série de práticas discursivas que, permeadas pelo poder, se orientam muito mais para produção de subjetividades através de uma rede de saberes, do que pela interdição. Daí a necessidade de pensar se o que está em jogo com a tramitação desses projetos de lei é mesmo uma tentativa genuína de fazer calar a escola sobre o sexo e o gênero - através da imposição de um silenciamento e da repressão desses temas - ou em questão está a (re)produção de um determinado regime de verdade, a partir da exigência de um silêncio tagarela que atua na proliferação de um conjunto de dizeres sobre a sexualidade e o gênero.

É por isso, que o foco deve recair no silenciamento enquanto uma prática discursiva, da qual a repressão não constitui seu caráter ou objetivo essencial, mas um de seus instrumentos e/ou efeito. O silêncio e o não-dizer sugeridos pela proibição da "ideologia de gênero" através da instituição de uma "escola sem partido" pertencem muito mais a uma ordem produtiva, do que repressiva, falam e (re)produzem muito mais que calam e reprimem, ambos são elementos discursivos. O silêncio e o não-dizer, enquanto tais, podem figurar como produtores e efeitos dos regimes de poder-saber num jogo complexo e instável em que não é submetido ao poder determinantemente, nem oposto a ele (FOUCAULT, 2015: 110).

Desse modo, apesar da aparência repressiva, há de se perceber, entretanto, que os empenhos reguladores contra o que se chama de "ideologia de gênero" não se tratam meramente de um fazer calar através da imposição do poder de um grupo sobre outro - dos grupos conservadores e religiosos sobre os movimentos feministas e LGBT. O poder não é uma coisa que um indivíduo ou grupo detém e exerce diretamente sobre outro indivíduo ou grupo, seu exercício, ao contrário, se dá como uma relação, "um conjunto de ações de indivíduos e/ou grupos que são induzidas e respondem a outras ações de outros indivíduos e/ou grupos" (FOUCAULT, 1995: 259). 
É justamente como uma relação de poder - e não da imposição de poder - que o fenômeno "antigênero" se caracteriza, já que ele faz parte de um espectro de ações de grupos conservadores e religiosos que reagem às diversas ações e pautas dos movimentos feministas e LGBT, e se configuram em torno da disputa pela ordenação dos dispositivos da sexualidade que perpassam nossa existência, alocados em nossas subjetividades e produtores de nossas práticas, nossos desejos e corpos. Nesse caso, o objeto das resistências dos grupos conservadores com relação à abordagem dos temas de gênero e sexualidade no campo da educação é conjunto de verdade-saber acerca do sexo e do gênero e a sua materialização no espaço escolar e na concretude do cotidiano.

Essa disputa é acionada pela potencialidade dos regimes de saber na ordenação das condutas e da construção da subjetividade a partir da sexualidade e do gênero. Não é à toa que ela se desdobra em torno da escola. O combate à chamada "ideologia de gênero" recai sobre esse espaço por dois motivos centrais: primeiro, porque existe, mesmo que de forma incipiente, um processo de defesa e incorporação desse tema pelas políticas educacionais brasileiras; e, segundo, principalmente, porque o ambiente escolar se trata de uma arena de disputa política.

Depois da instituição familiar, a escola é o espaço nos processos de socialização através do qual os indivíduos acessam o mundo e a sua subjetividade. Ela se constitui como lugar privilegiado na constituição dos sujeitos, no qual, dentre muitos outros, os indivíduos aprendem a se reconhecer como dotados de sexualidade. É preciso pontuar que para Foucault (1995: 235) a "iluminação" do sexo é operada no interior de mecanismos de saber-poder, dentre os quais estão discursos, as instituições e as práticas. A escola é uma dessas instituições, que por excelência atua na proliferação dos regimes de saber-poder do sexo.

$\mathrm{Na}$ instituição escolar circulam práticas e mecanismos de poder/saber, isso faz dela um espaço institucional de poder-desejo que produz e reflete as concepções de gênero e sexualidade que circulam na sociedade (LOURO, 1997: 80-81). As práticas escolares não se restringem à transmissão do saber, mas também, e essencialmente, da constituição de sujeitos masculinos, femininos e heterossexuais. Os currículos, as práticas, as normas, a linguagem, os materiais didáticos, os procedimentos avaliativos são construídos a partir de relações de gênero e produtores delas, ao mesmo tempo (LOURO, 1997: 64). 
Apesar das reificações das concepções e relações de gênero e sexualidade que costuram o corpo social estarem presentes na escola, elas não são apresentadas de modo aberto quiçá pelas resistências aos padrões a nós impostos. Muitas vezes as questões que envolvem o gênero e a sexualidade ficam submersas na paisagem escolar como temas que devem ser tratados fora da escola. Ocorre daí o enganoso silenciamento dessas questões que opera como um dispositivo que de um lado, omite/reprime os sujeitos e as condutas sexuais que escapam dos modelos de gênero e da sexualidade esperados, e, de outro, reifica esses modelos e contribui para o estabelecimento de uma matriz heterossexual. Entretanto, essas questões estão e fazem parte da escola inevitavelmente, uma vez porque não podem ser desligadas dos sujeitos que circulam por ela, o problema consiste no modo como elas são ou não abordadas no cotidiano escolar (LOURO, 1997: 131).

Nessa esteira, o impasse que marca as possibilidades de questionamento dos temas de gênero e sexualidade no ambiente escolar se dá em torno da verdade, no sentido foucaultiano, que deve ir à escola sobre as categorias de gênero e a sexualidade e as relações baseadas nelas. E isso se evidencia pelas demandas de proibição da chamada "ideologia de gênero" que recorrem ao imperativo de silenciamento dessas questões fundamentado na proliferação de um conjunto de saberes sobre a sexualidade, relações e práticas dele resultantes - daí a produção de silêncios tagarelas produtores de subjetividades.

Com isso, sugerimos que essas reivindicações e as propostas de lei que delas emergem estão inevitavelmente ligadas à caça pela verdade do sexo que se impôs na modernidade através do que Foucault (2015) chama de "dispositivo da sexualidade". Isso nos leva a considerar os projetos de lei como dispositivos jurídicos sustentados por um por um saber jurídico mobilizado para afirmar/reificar um conjunto de outros saberes que circulam em torno de uma série de disputas pelo status da verdade no campo das relações de saber/poder acerca do binômio sexo-gênero.

O temor que movimenta o combate à "ideologia de gênero" se dá pela ameaça de que o sexo deixe de ser visto como elemento natural e fixo. Isso é entendido como um problema, uma vez que sem a possibilidade de definir o sexo dos sujeitos, torna-se mais borrada a demarcação e regulação de sua experiência sexual nos limites da "normalidade natural", do desvio e da "anormalidade". 
Nanduty

ISSN:2317-8590

\section{CONSIDERAÇÕES FINAIS}

As provocações de Michel Foucault sobre as interrelações entre poder-saber-verdade sugerem que não se deve olhar para as propostas de lei voltadas para o silenciamento do espaço escolar do sistema educacional brasileiro no Congresso Nacional, em busca de localizar nelas pontos fixos e estáveis de poder, além de indicar a necessidade de certo cuidado com enfoques que enquadrem essas investidas no campo da repressão e da interdição - o que exige, obviamente, cautela e desconfiança com relação às expressões como silenciamento, censura, proibição, etc. O que está em jogo não está no fim (nem o começo) da introdução do gênero e da sexualidade nas políticas de educação, mas diferentes estratégias de poder/saber que se articulam através das disputas em torno da presença desses temas no espaço escolar.

A formulação de uma lei implica na produção de verdades a partir de uma fundamentação legal que institui um conjunto de verdades que lhe assegura o caráter de validade. Como foi demonstrado, é possível perceber no movimento das repetições das propostas de leis aqui analisadas, a existência de uma articulação discursiva que busca instituir nos documentos que balizam a educação no Brasil quaisquer discussões e a transmissão de conhecimentos que possam ferir a moralidade pautada nos valores religiosos, familiares e morais. Nesse contexto, uma atenção especial é dada a possibilidade de existência do debate nas escolas brasileiras das questões de gênero e sexualidade, que ganham no arrazoado das propostas de lei e nas narrativas dos sujeitos favoráveis a elas a designação pejorativa de "ideologia de gênero".

As propostas de lei apresentadas se constituem fenômenos privilegiados para observar como se movimentam os atores sociais envolvidos nas disputas que atravessam o cenário educacional e as políticas sexuais. Mesmo que não seja possível observar o resultado imediato delas sobre os horizontes normativos do sistema de ensino, uma vez que parte delas ainda está em trâmite, é possível identificar - através dos discursos mobilizados por elas e pelos diversos sujeitos, tanto no Congresso, como na sociedade civil - alguns de seus efeitos de poder-saber sobre o campo educacional. De certo modo, incide também sobre as possibilidades de ampliação dos processos de "cidadanização" das minorias sexuais, que está intimamente relacionada ao próprio alargamento da democracia. 
Afirma-se isso por considerar que mesmo que ainda não tenham sido transformadas em lei (e espera-se que não sejam), essas proposições produzem múltiplas repercussões no cotidiano. Suas demandas têm protagonizado em diversas ocasiões no debate público acerca da educação e no que tange aos temas e questões de gênero e sexualidade. Elas chegam às diversas redes e meios de comunicação, nas conversas informais entre as pessoas no dia-a-dia, nos noticiários, na escola, na sala de aula, alocando-se e se distribuem pelo corpo social através de narrativas que alimentam e (re)produzem pânicos morais. Estes - como já exposto marcam o receio com relação aos perigos da chamada "ideologia de gênero" para as crianças e para as famílias e, também as próprias reações dos movimentos sociais às estratégias de deslegitimação do reconhecimento dos direitos das mulheres e da população LGBT (MISKOLCI, 2007: 110).

Deste modo, é possível estabelecer uma leitura dessas propostas em busca de suas conectividades a partir da noção de capilaridade do poder de Foucault (1998) em dois sentidos articulados. Primeiramente, os discursos acionados pelas proposições evidenciam a capilaridade própria dos dispositivos de sexualidade pelos regimes de verdade-saber e pelo imperativo de reificação do caráter natural do sexo que elas invocam. Em segundo lugar, há de se perceber que essas narrativas que atravessam e compõem os projetos de lei não circulam apenas em suas páginas, elas perambulam em outros espaços através de um movimento, para o qual "talvez o mais importante seja a disputa pela opinião pública", a aderência e a força que suas ideias estão ganhando "dentre alguns segmentos da sociedade civil" (PENNA, 2017: 36).

Conclui-se que por detrás do pânico moral em torno da "ideologia de gênero" escondem-se temores diversos com relação às transformações que podem ser operadas na sociedade a partir do questionamento do caráter natural do sexo. As propostas de proibir esse processo na escola se inclinam no sentido de silenciar o espaço escolar com relação aos temas de gênero e sexualidade. Mas se trata da imposição de um silêncio tagarela, que atua na proliferação de um conjunto de verdades sobre os marcadores de sexo e de gênero que os assinala como fruto da natureza, o que contribui diretamente para a reprodução e perpetuação da estigmatização, de preconceitos, discriminações e violências diversas sobre as minorias sexuais. A questão é que a não discussão e o silêncio sobre temas em sala de aula legitima esses saberes que patologizam os sujeitos e práticas que não se enquadram nos padrões 
construídos socialmente de normalidade. A sua legitimação é (re)produtora de práticas discriminatórias, preconceituosas e violentas que marcam o cotidiano dos sujeitos dissidentes das coerências e normas de gênero e lhes negam, muitas vezes, o próprio direito à existência.

\section{REFERÊNCIAS BIBLIOGRÁFICAS}

BUTLER, Judith. Problemas de gênero: Feminismo e subversão da identidade. Tradução de Renato Aguiar. Editora Civilização Brasileira, 11 ed. Rio de Janeiro, 2016.

CÂMARA DOS DEPUTADOS. 2014. Projeto de Lei $\mathbf{n}^{\mathbf{0}}$ 7180/2014. Inteiro teor. - Brasília, DF, 2014.2 In: http://www.camara.gov.br/proposicoesWeb/prop_mostrarintegra;jsessionid=91CE19FE 20C4576DB3BCB6DB01BD9595.proposicoesWebExterno1?codteor $=1230836 \&$ filena $\mathrm{me}=\mathrm{PL}+7180 / 2014$ (acessado em jun. 2017).

. 2014a. Discursos e notas taquigráficas: Comissão Especial PL 8035/2010 - Plano Nacional de Educação. - Brasília, DF, $2014 . \quad$ In: http://www2.camara.leg.br/deputados/discursos-e-notas-taquigraficas/discursos-emdestaque/plano-nacional-de-educacao/comissao-especial-pl-8035-2010-ano-de-2014 (acessado em jun. 2017).

2015. Projeto de Lei $\mathbf{n}^{\mathbf{0}}$ 1411/2015. Inteiro teor. - Brasília, DF, 2015. In: http://www.camara.gov.br/proposicoesWeb/prop_mostrarintegra?codteor=1330054\&fil ename $=P L+1411 / 2015$ (acessado em jun. 2017).

, 2015a. Projeto de Lei $\mathbf{n}^{\circ}$ 1859/2015. Inteiro teor. - Brasília, DF, 2015. In: http://www.camara.gov.br/proposicoesWeb/prop_mostrarintegra?codteor=1346799\&fil ename $=$ PL+1859/2015 (acessado em jun. 2017).

, 2015b. Projeto de Lei $\mathbf{n}^{\circ}$ 2731/2015. Inteiro teor. - Brasília, DF, 2015. In: http://www.camara.gov.br/proposicoesWeb/prop_mostrarintegra?codteor=1374936\&fil ename $=P L+2731 / 2015$ (acessado em jun. 2017).

, 2016. Projeto de Lei 5487/2016. Inteiro teor. - Brasília, DF, 2016. In: http://www.camara.gov.br/proposicoesWeb/prop_mostrarintegra?codteor=1465056\&fil ename $=$ PL+5487/2016 (acessado em jun. 2017)

2017. Projeto de Lei 8933/2017. Inteiro teor. - Brasília, DF, 2017. In: http://www.camara.gov.br/proposicoesWeb/prop_mostrarintegra;jsessionid=394AB7B D0770E705F9AC0F701E68AB72.proposicoesWebExterno2?codteor=1614020\&filena me $=$ PL+8933/2017 (acessado em jan. 2018). 
CARRARA, S. Moralidades, racionalidades e políticas sexuais no Brasil contemporâneo. Rev. Mana, v. 21, n. 02, pp. 323-345, 2015.

FOUCAULT, Michel. História da sexualidade I: a vontade de saber. Trad. Maria Thereza da Costa Albuquerque e J. A. Guilhon Albuquerque. 2 ed. - São Paulo, Paz e Terra, 2015.

Microfísica do Poder. Org. e Tradução de Roberto Machado. - Rio de Janeiro, Edições Graal, 1998.

GONÇALVES, R. A atuação de Marco Feliciano na Comissão de Direitos Humanos e Minorias (CDHM). Rev. Mandrágora, São Paulo, v. 23, n. 2, 2017, pp. 205-245.

JUNQUEIRA, Rogério Diniz. "Ideologia de gênero": a gênese de uma categoria política reacionária - ou: a promoção dos direitos humanos se torou uma "ameaça à família natural? In: RIBEIRO, P. MAGALHÃES, J. Debates contemporâneos sobre educação para a sexualidade. - Rio Grande: Ed. Da FURG, 2017.

LISPECTOR, Clarice. Água Viva. Editora Rocco. Rio de Janeiro, 1998.

LOURO, Guacira Lopes. Gênero, sexualidade e educação: uma perspectiva pósestruturalista. Petrópolis, RJ: Vozes, 1997.

MACHADO, Lia Zanotta. Feminismos brasileiros nas relações com o Estado. Contextos e incertezas. Cad. Pagu, Campinas, v.47, 2016.

MELLO, Luiz. Novas famílias: conjugalidade homossexual no Brasil contemporâneo. - Rio de Janeiro: Garamond, 2005.

MIGUEL, Luís Felipe. Capital político e carreira eleitoral: algumas variáveis na eleição para o Congresso brasileiro. Revista de Sociologia e Política, n. 20, Curitiba, 2003, pp. 115-34.

Da "doutrinação marxista" à "ideologia de gênero" - Escola Sem Partido e as leis da mordaça no parlamento brasileiro. Rev. Direito e práxis, Rio de Janeiro, v.07, n.15, pp. 590-621, 2016

MISKOLCI, Richard. Pânicos morais e controle social - reflexões sobre o casamento gay. Cad. Pagu [online], n. 28, jan-jun, pp.101-128, 2007.

Estética da existência e pânico moral. In: RAGO, M. Veiga-Neto (Org.s). Figuras de Foucault. 2ed. - Belo Horizonte: Autêntica, 2008.

CAMPANA, Maximiliano. "Ideologia de gênero": notas para a genealogia de um pânico moral contemporâneo. Rev. Sociedade e Estado, v. 32, n. 03, set-dez, pp.725-747, 2017. 


\section{PATRIOTA51. Projeto de lei de autoria do deputado Erivelton Santana "Escola Sem} Partido", tramita na Câmara desde 2014. Disponível em: $<$ http://patriota51.org.br/projeto-de-lei-de-autoria-do-deputado-erivelton-santanapatriotaba-escola-sem-partido-tramita-na-camara-dos-deputados-desde-2014/.> Acesso em: 15 dez 2017.

PENNA, Fernando. O Escola sem Partido como chave de leitura do fenômeno educacional. In: FRIGOTTO, G (Org). Escola "sem" Partido: esfinge que ameaça a educação e a sociedade brasileira. - Rio de Janeiro: UERJ, LPP, 2017.

PRECIADO, Paul Beatriz. Manifesto contrassexual. - São Paulo: n-1 edições, 2017.

ROSADO-NUNES, Maria José Fontelas. A “ideologia de gênero" na discussão do PNE. A intervenção da hierarquia católica. Rev. Horizonte, Belo Horizonte, v. 13, n.39, pp.1237-1260, jul-set. 2015.

RUBIN, Gayle. Pensando sobre Sexo: notas para uma teoria radical da política da sexualidade. Cad. Pagu, n. 21, 2003.

SANTANA, Erivelton. Documentário 01 - Deputado Erivelton Santana. Disponível em: < https://www.youtube.com/watch?v=0F_QrNpnsw4>. Acesso em: 15 dez 2017.

SEFFNER, Fernando. Atravessamentos de gênero, sexualidade e educação: tempos difíceis e novas arenas políticas. In: Reunião Científica Regional da ANPED: Educação, movimentos sociais e políticas governamentais. 24 a 27 de julho de 2016, UFPR, Curitiba, Paraná.

SENADO FEDERAL, 2016. Projeto de Lei do Senado n⿳ 193/2016. Inteiro teor. - Brasília, DF, $2016.2 \quad I n: \quad$ https://legis.senado.leg.br/sdleggetter/documento?dm=569947\&disposition=inline (acessado em jun. 2017). 